\title{
De una Iberia peninsular a la Hispania romana
}

\author{
Federico FERnÁndez de BujÁn \\ Universidad Nacional de Educación a Distancia \\ fdebujan@der.uned.es
}

\begin{abstract}
RESUMEN
Este año 2014 conmemoramos el bimilenario de la muerte de Octavio Augusto. Bajo su mandato como un logro más de la Pax Augusta una Roma esplendorosa culmina la romanización de nuestro suelo. Afirmar que Roma conquista España constituye un error pues no es posible conquistar aquello que no existe todavía. Es cierto que frente a las legiones romanas, durante dos largos y cruentos siglos, luchan una diversidad de pueblos indígenas. Sin embargo, no son españoles quienes se enfrentan a las legiones romanas, sino turdetanos, ilergetes, celtíberos, vacceos, etc. Sólo cuando, tras la pacificación augusta toda esa diversidad de pueblos y culturas se funden en la romanización operada, Roma y su administración provincial hacen surgir una unidad política, Hispania, que alcanza un concepto y una realidad que llega a superar, por vez primera en su historia, lo que hasta entonces no pasaba de ser mero concepto topográfico basado en una simple configuración peninsular.
\end{abstract}

Palabras clave: Pax Augusta. Conquista. Romanización.

\section{From the Iberian Peninsula to the Roman Hispania}

\begin{abstract}
This 2014 we conmemorate Octavio Augustus death's bimillenary. Under his command, as just another achievement of the Pax Augusta, a magnificent Rome culminated the Romanization of our land. To state that Rome conquered Spain would be mistaken, as it is not possible to conquer something that does not yet exist. It is true that against Roman legions a great diversity of indigenous peoples fought for two long and bloody years. However, they were not Spaniards, but "turdetanos, ilergetes, celtíberos, vacceos", etc, those who faced the Roman legions. Only after the Augustan pacification, when all the peoples' diversity and culture merge with the Romanization, Rome and its provincial administration achieved to create a new political unit, Hispania, which reached to exceed, for the first time in its history, what until that time was not more than a topographical concept based on simple peninsular configuration.
\end{abstract}

Key Words: Pax Augusta. Conquest. Romanization.

Sumario: 1. Proemio poético. 2. Preludio reflexivo. 3. Roma arriba a Iberia. 4. El marco provincial de Hispania. 5. La ciudad, base de la administración de la península. 6. Algunos datos económicos de la Hispania romana. 7. Postfatio. 


\section{Proemio poético}

Este año 2014 conmemoramos el bimilenario de la muerte de Octavio Augusto. Bajo su mandato -al inicio de la primera centuria cristiana y como un logro más de la Pax Augusta o Paz Octaviana-, una Roma esplendorosa culmina la romanización de nuestro suelo y otorga conciencia de unidad a esta tierra y a sus gentes. Lo que era solo un mero accidente geográfico, sin otra identidad que su configuración peninsular, se convierte -por vez primera y con fecunda proyección histórica hasta hoy-, en granada y gozosa realidad política de convivencia en común.

Roma conforma España. Esta afirmación constituye una oración compuesta por dos sustantivos unidos por un verbo. El primero reseña una realidad histórica que fue y ya no es. El segundo refiere una realidad histórica que fue, ha sido y es. El verbo que enlaza uno y otro sustantivos, "conformar", ofrece, en su prístino significado, un concepto que va más allá de las nociones de relacionar o encadenar. Trata de expresar, en la primera acepción que ofrece el Diccionario de la Real Academia Española, la idea "de concordar algo con otra cosa". Si continuamos con nuestra sencilla reflexión lingüística, por remisión, hemos de aproximamos al concepto de concordar, que deriva del latín concordare, y de ahí concordancia, concordia. Esta es la idea que se nos ofrece en esta segunda acepción de conformar cuando el Diccionario, referida a las cosas y no a las personas, expresa que conformar es corresponder una con otra, añadiendo, en su tercera acepción de conformar la realidad de estar en concordancia, es decir, en conformidad o correspondencia.

Pues bien, desde de este apunte semántico, pretendo exponer cómo Roma, una espléndida realidad histórica pretérita, una de las experiencias más brillantes de la historia de la humanidad que hoy en su aletea, espíritu y en sus instituciones, en la cultura y en la civilización occidental, ha conformado con sus propios mimbres esta realidad multisecular nuestra que llamamos España. Una realidad sociopolítica que, siglos más tarde de haber sentido la presencia político-administrativa y cultural de la civilización romana, sentirá la necesidad de constituirse, configurándose como una nación que precisa ser dotada de una estructura jurídica estatal. Ese Estado moderno, el primero en constituirse en nuestro continente europeo que, desde hace ya más de cinco siglos, nos ha sido legado. En él, a pesar de ciertos intentos actuales desconstructores, podemos decir, parafraseando a San Pablo, que los españoles, con encuentros y desencuentros, amores y desamores, con gozos y sombras, "vivimos, nos movemos y existimos".

Y si esto es así, al menos hasta el tiempo presente, lo es porque en una etapa que coincide, poco más o menos, con el cambio de cómputo en nuestra cronología como forma de datar los hechos, es decir, en los últimos años de la era precristiana y en los inicios del primera centuria de la era cristiana, Roma ha conformado un territorio y a sus habitantes, entregándoles una conciencia de unidad a lo que hasta entonces era solamente un accidente geográfico sin más identidad que su configuración peninsular.

Analicemos, pues, nuestra actual realidad constitucional y democrática desde sus orígenes, tomemos las aguas desde arriba en este torrente de vivencias sociales y políticas y podremos encontrarnos en mejores condiciones de continuar discurriendo las 
mejores formas y las más adecuadas fórmulas para que nuestra convivencia nacional siga ofreciendo una estadio habitable y un proyecto viable por el que discurran las inquietudes, zozobras e ilusiones de un pueblo que se sintió hispano al integrarse, como un todo unitario, en el vasto ámbito de la romanidad. Resulta comúnmente admitido, que para realizar un adecuado análisis acerca del sentido de cualquier institución jurídica o para alcanzar una correcta interpretación del contenido de una norma, el estudioso del Derecho debe previamente conocer y comprender el marco históricosocial en que dicha disposición normativa ha sido promulgada y aplicada.

La vida social del hombre y el devenir de las sociedades en la que aquella se desenvuelve, es siempre un prius respecto al marco jurídico que las ordena y las regula. El Derecho acompaña a la vida, pues, es ésta quien lo condiciona y modifica. Es así el Derecho un producto histórico, que nunca debe desvincularse del marco social al que va a ser aplicado. Lo contrario implicaría correr el riesgo de convertir el orden jurídico en una entelequia artificial y por ello inservible. Y si la vida social condiciona la tarea de conformación del Derecho, del mismo modo aquella debe ser informante en la tarea de su correcta interpretación. A fin de prologar este estudio con algún testimonio que pueda expresar el núcleo y el hilo conductor que va a constituir su nervio vital, me parece oportuno dar voz a dos poetas que, en tiempos recientes, han sabido encerrar en sus versos el alma y el espíritu de ese pueblo, ayer y hoy romano, que habitó en esta piel de toro.

Serán así ellos, quienes sirvan de atalaya para reflexionar sobre la profunda huella que dejó la cultura y la civilización romana en el territorio peninsular. Lo hago desde la profunda convicción de que sólo la poesía, con su proverbial penetración en el espíritu popular, puede desentrañar la esencia vital del pueblo al que sirve y del que nace. "Aire de Roma andaluza / le doraba la cabeza". Así se expresa uno de los poetas más sensibles y geniales de nuestra poesía contemporánea, el llorado Federico García Lorca. Con esa intuición propia de los poetas, en su sentida elegía que expresa el "Llanto por Ignacio Sánchez Mejías" dice Lorca: "Aire de Roma andaluza...” y lo hace, en sublime expresión, sabedor que nada como Roma expresa el noble pensar, sentir y vivir de este pueblo.

Hispania fue probablemente una de las más brillantes provincias romanas. Ese mismo territorio se convirtió, siglos más tarde, como consecuencia de la invasión islámica y de su intrínseca vis expansiva, en la realidad más floreciente de toda la historia de la civilización musulmana, esto es, en El Andalus con capital en la Córdoba califal. A esta bifronte realidad histórica se refiere, de nuevo, otro poeta, ahora, Manuel Machado, en una preciosa poesía en la que a través de una sola estrofa es capaz de definir el alma de cada una de las capitales andaluzas. Y de Córdoba dice: "Romana y mora, Córdoba callada".

Sin duda, una y otra realidades, romana y musulmana, se configuran en Córdoba y por extensión en toda la península, con un arco histórico de parecidas dimensiones cronológicas, alrededor de siete siglos. Sin duda también, sólo una, la huella romana, se ha grabado en España como huella indeleble e imperecedera. En este sentido, puede afirmarse que Roma ha conformado con sus propios mimbres la primera Historia 
de España. Aún más, entiendo que debe afirmarse con notoria certeza que: España es una creación de Roma.

\section{Preludio reflexivo}

Afirmar que Roma conquista España constituye un evidente error de perspectiva, ya que no es posible conquistar aquello que no existe todavía. Es cierto que frente a las legiones romanas, durante dos largos y cruentos siglos, luchan una diversidad de pueblos indígenas. Sin embargo, no son españoles quienes se enfrentan a las legiones romanas, sino turdetanos, ilergetes, celtíberos, vacceos, etc. Sólo cuando, tras la pacificación augusta toda esa diversidad de pueblos y culturas se fundieron en la romanización operada, Roma y su administración provincial hicieron surgir una unidad política, Hispania, que alcanza un concepto y una realidad que llega a superar, por vez primera en su historia, lo que hasta entonces no pasaba de ser mero concepto topográfico basado en una simple y concreta configuración geográfica-peninsular.

Suele afirmarse que la historia de Roma es la historia de una ciudad que se ensancha para convertirse en la historia de un país y termina siendo la historia del mundo. Su larga etapa de conformación y crecimiento puede asemejarse a la perenne lozanía de un árbol, de cuyo tronco germinan permanentemente nuevos brotes. Una de las más frondosas ramas de esta colosal civilización romana fue la antigua Shepham-im de los fenicios y la Iberia de los griegos: un territorio mítico en el que se producía el ocaso del sol, allí donde Hércules formó sus columnas y venció al monstruoso rey Gerión, en suma, el finis terrae tras el cual se abría el misterioso y proceloso MarOcéano.

Hispania en general formará pronto parte importante de la historia romana. La romanización en la península será tan rápida que, en pocos años, ya no tendrá sentido distinguir entre un romano de Roma o uno de Itálica, Malaca, Corduba o Gades. A propósito de esta plena fusión de pueblos Veleyo Patérculo afirma que Cornelio Balbo, amigo y colaborador de César, nacido en Gades, era non Hispaniensis sed Hispanus. Así en

...illis incrementis fecit viam, quibus non in Hispania ex cive natus, sed Hispanus, ia triumphum et pontificatum adsurgeret fieretque ex privato consularis...

Vell. Pat., 2.51

Hispania aportará a la Urbs, de forma pródiga, gran abundancia de productos agrícolas y riquezas mineras; proporcionará pensadores y emperadores ilustres tales como Séneca o Quintiliano, Trajano o Adriano y en su territorio se librarán cruentas guerras civiles con Sertorio, Pompeyo y Julio César que, sin duda, repercutirán en la política general de todo el Imperio. Contrariamente a lo que cabría suponer, las guerras civiles desarrolladas en el territorio peninsular hispano entre las tropas de César y los ejércitos de Pompeyo, en vez de provocar un efecto distanciador y de rechazo de la civitas, contribuyeron, de forma decisiva, a hacer a Hispania cada vez más romana. Así se expresa César en Bell. Alex., 42 y aún más explícito en, 
Caesar contione habita Cordubae omnibus generatim gratias agit: civibus Romanis, quod oppidum in sua potestate studuissent habere; Hispanis, quod praesidia expulissent; Gaditanis, quod conatus adversariorum infregissent seseque in libertatem vindicassent; tribunis militum centurionibusque, qui eo praesidii causa venerant, quod eorum consilia sua virtute confirmassent. Pecunias, quas erant in publicum Varroni cives Romani polliciti, remittit; bona restituit eis, quos liberius locutos hanc poenam tulisse cognoverat. Tributis quibusdam populis publicis privatisque praemiis reliquos in posterum bona spe complet biduumque Cordubae commoratus Gades proficiscitur; pecunias monumentaque, quae ex fano Herculis collata erant in privatam domum, referri in templum iubet. Provinciae Q. Cassium praeficit; huic III legiones attribuit. Ipse eis navibus, quas M. Varro quasque Gaditani iussu Varronis fecerant, Tarraconem paucis diebus pervenit. Ibi totius fere citerioris provinciae legationes Caesaris adventum exspectabant. Eadem ratione privatim ac publice quibusdam civitatibus habitis honoribus Tarracone discedit pedibusque Narbonem atque inde Massiliam pervenit. Ibi legem de dictatore latam seseque dictatorem dictum a $M$. Lepido praetore cognoscit

Roma nos lega su idioma y su manera de concebir la vida social, levanta templos y monumentos, construye obras públicas y calzadas, transmite su derecho y la organiza a través de sistema político-administrativo, tanto provincial como ciudadano. En suma, Hispania se identifica con Roma y fruto de ello se asemeja y emula a la civitas, en suma, se civiliza. Así, se encarnó de forma especial aquel justo elogio a la romanidad, y por ende a la romanización, que Elio Arístides pronuncia ante el emperador Antonino Pío durante una visita a la Urbs:

"Como el suelo fértil de la tierra mantiene a todos los hombres, así Roma recibe a hombres de toda la tierra... en sus ciudades, muchos son romanos, aunque los más no hayan visto jamás la ciudad de Roma... Y no hay necesidad de guarniciones que ocupen las acrópolis, pues gracias a una constitución común... los que gobiernan lo hacen no sobre extranjeros sino sobre compatriotas"

Y si Roma crea a Hispania, la vida de ésta se funde inseparablemente con la de aquella. Hispania dejará de ser romana, como consecuencia de la conquista de los pueblos visigodos en el 475 d.C., cuando Eurico, rey visigótico, deja de reconocer la soberanía del último emperador de Occidente. Repárese que Hispania deja de ser Hispania cuando Roma deja de ser Roma. Solamente unos meses más tarde Flavio Rómulo Augusto -denominado por sus enemigos "Augústulo" como "pequeño Augusto"- el 4 de septiembre de 476 depone las armas ante Odroaco y se produce la caída del Imperio de Occidente.

Sin duda, los distintos pueblos y reinos visigóticos que, inmediatamente, pueblan las diversas regiones de España no se alejan mucho de las realidades socioculturales que estaban presentes en la Hispania romana, ya que unos y otros son simples herederos de un Imperio, que acabó cediéndoles la propia romanidad en la que habían crecido y se habían conformando.

Conviene no olvidar que la presencia visigótica en nuestro suelo encuentra su origen en el año 418 d.C., en el que el pueblo visigodo recibió de las autoridades ro- 
manas licencia para instalarse en el territorio peninsular, de acuerdo con las leyes de la hospitalidad. En este sentido, los monarcas germanos no fundan España sino que la reciben, como legado precioso, de manos romanas. La propia denominación que adoptan, España, es una derivación de Hispania. Sorprende así, que no se denomina a nuestro reino Gotia como hubiera sido lógico según el modelo de otras monarquías germanas. Ello es prueba incontestable que el principal componente político-jurídico y socio-cultural con el que se encuentran y del que parten para la recomposición nacional es el elemento hispano-romano.

Y si esto es así en el terreno colectivo, no lo es menos en el plano individual. En este sentido, si quisiéramos destacar en la nueva situación política una personalidad descollante sobre cualquier otra, no podríamos referirnos a un monarca germano ni a un godo destacado en las tareas de gobierno. Es indudable que, en este período, nadie brilla con luz semejante a San Isidoro, un sabio hispano-romano, inspirador y consultor de los reyes, que ocupa la diócesis hispalensis hacia el año 600 de nuestra era. El denominado Doctor Hispalense personifica la grandeza intelectual y literaria de la Monarquía visigoda y se convierte en manantial inagotable que inundará, durante siglos, la actividad intelectual y cultural europea. Isidoro es el primero que, una vez caído el Imperio de Occidente, es capaz de trasladar, y además en forma lírica, el elocuente eco con que la grandeza de Roma es capaz de sonar desde sus propias ruinas.

La invasión musulmana, que se inicia en el 711, produce una disgregación de la unidad nacional visigótica recibida de la romana. Durante más de siete siglos una pluralidad de fuerzas políticas, que acaban configurando un desordenado y caótico reino de taifas, se instalan en la vieja piel de toro, superficie de nuestro solar patrio. Y cuando parecía que la huella romana había desaparecido como consecuencia de la secular presencia musulmana, los reinos cristianos logran, paulatinamente, reconquistar la península. De nuevo en este momento histórico, será la Bética la región desde la que los reyes de Castilla vuelven a romanizar nuestra península, que recobra su nombre y se identifica a sí misma como una indisoluble unidad nacional.

Fruto de esta segunda romanización -que en Sevilla se produce a partir del siglo XIII con la conquista de la ciudad por el Rey Fernando III el Santo y en todo el territorio peninsular a partir del siglo XVI con la toma de Granada por los Reyes Católicos y la definitiva configuración de España como Estado nacional-, nuestra península vuelve a tener una unidad común a todos sus pueblos y comienza a conformarse la Historia moderna y contemporánea de la España actual.

\section{Roma arriba a Iberia}

Roma penetra con sus legiones en la península ibérica en el año 218 a.C. La denominación griega de Iberia, según Estrabón, no es unívoca, pues, con ella se refiere, según unos u otros historiadores, diversas zonas no bien identificadas de la península, Estrabón, 4.4.19. El mismo historiador, -en 3.4.19-, manifiesta que es difícil determinar de forma precisa cuántos y cuáles sean los pueblos pobladores de Iberia, debido, en primer lugar, al pequeño tamaño y entidad de los mismos y, en segundo 
lugar, a la falta de rigor de que adolecen los textos por él consultados, de historiadores griegos y romanos que habían ofrecido su testimonio sobre la etapa prerromana y los primeros momentos de la presencia de Roma en estas tierras.

En ese año 218 a.C., las tropas de los Escipiones se disponen a atacar e intentan derrotar al enemigo cartaginés que se encarna en la poderosa familia de los Barca, encabezada por un joven, Aníbal, que, por entonces, pretendía mantener su guerra de conquista en la península itálica. Se iniciaba así la segunda guerra púnica. Es entonces, como recuerda Livio (21.17.1), cuando Hispania es adscrita por el Senado como provincia romana.

Nominatae iam antea consulibus provinciae erant; tum sortiri iussi. Cornelio Hispania, Sempronio Africa cum Sicilia evenit Liv., 21.17.1

En este primer momento la resolución senatorial reviste, simplemente, el carácter de una simple decisión militar. Se asignó el imperium a Publio Cornelio Escipión. La consideración de Hispania como provincia, tal como indica Zonaras (9.10.433), no implica en este primer estadio, una demarcación de su territorio ni siquiera una decidida y firme voluntad de permanencia. La decisión del Senado de Roma se limita a configurar una zona de interés militar situada más allá de los Pirineos y a delimitar una auténtica demarcación administrativa.

En el 206 a.C. los cartagineses son expulsados definitivamente de la península. Este mismo año, los generales Cornelio Lentulo y Manlio Acidimo fueron investidos de imperium pro consulare. En este sentido, son contingencias de política militar, las que llevan a Roma a establecer e implantar un doble mando permanente. No puede saberse con certeza, debido a contradicciones en la misma fuente-Livio, 29.13.7 vs. Livio, 30.41.4-, si uno y otro son enviados a una sola provincia que se encomienda a dos mandos o si, por el contrario, se trata de dos nombramientos independientes referidos a dos provincias diferentes.

de Hispaniae imperio, quos in eam provinciam duos pro consulibus mitti placeret latum ad populum est. omnes tribus eosdem L. Cornelium Lentulum et L. Manlium Acidinum pro consulibus, sicut priore anno tenuissent, obtinere eas provincias iusserunt...

Liv., 29.13.7

...quod ad Hispanias attineret, aliquot annos iam ibi L. Cornelium Lentulum et $L$. Manlium Acidinum esse; uti consules cum tribunis agerent ut si iis videretur plebem rogarent cui iuberent in Hispania imperium esse...

Liv., 30.41 .4

En el 197 a.C. el doble mando militar fue sustituido por dos propretoribus a los que el Senado encomienda expresamente que delimiten el territorio de cada una de las provincias Citerior y Ulterior. Así se expresa en, 
Praetoribus in Hispanias octona milia peditum socium ac nominis Latini data et quadringeni equites, ut dimitterent ueterem ex Hispaniis militem; et terminare iussi qua ulterior citeriorue prouincia seruaretur...

Liv., 32.28 .11

La nueva regulación senatorial establece como frontera provincial el saltus Castulonensis (Cástulo, en la actual provincia de Jaén). Esta localidad había tenido cierto protagonismo en la segunda guerra púnica. En un primer momento se había aliado con Cartago pero más tarde se decanta por Roma, que hace radicar sus inmediaciones como escenario de sus operaciones bélicas. La Roma victoriosa concede en gratitud a la ciudad distintos privilegios así como el control económico sobre los yacimientos metalíferos de Sierra Morena Oriental.

Cástulo estableció con Roma un foedus que la convertía en ciudad libre e inmune, parcialmente, del pago de tributos. En contrapartida se compromete a albergar una guarnición romana y a proporcionar tropas en caso de conflictos bélicos. Entre los años 80-45 a.C. Cástulo acuña monedas manteniendo sus antiguos símbolos de la esfinge y el toro e incorporando una figura femenina sobre el toro, lo que tradicionalmente se asocia con el rapto de Europa. Es de destacar que sus monedas se extendieron por toda Hispania Ulterior.

\section{El marco provincial de Hispania}

Interrumpiendo esta breve narración cronológica, voy a ceñirme a partir de este momento, a discurrir acerca del proceso evolutivo producido durante los primeros siglos de nuestra era, por ser éste el marco de nuestro congreso. No obstante, debo iniciar este relato sucinto con lo sucedido en los últimos años de la República, por ser en ellos donde la etapa siguiente reconoce su origen y causa.

Al llegar César al poder se encuentra con catorce provincias, de las que siete están en territorio europeo y de ellas dos en el territorio peninsular denominado Hispania: son éstas, la Hispania citerior, con capital en Carthago Nova y la Hispania ulterior, con capital en Corduba. Esta doble división era a fines de la República manifiestamente artificial por no responder efectivamente a la realidad geográfico-social a la que se refería.

Al reorganizarse con carácter general, a partir del año 27 a.C., la administración del Imperio, se asigna a Octavio Augusto el control peninsular en atención a que se proyecta emprender en ella operaciones militares de cierta envergadura, para lo cual era necesario destacar guarniciones permanentes. Augusto se traslada a España y fija en Tarraco su residencia durante los años 26 y 25 a.C. Organiza sobre el terreno las campañas guerreras del norte y reordena la administración provincial. Convierte a Tarraco en la nueva sede del gobierno de la Hispania citerior, que antes estaba en Carthago Nova. Fruto de ello, esta provincia pasa a denominarse Tarraconense. La nueva capital tenía la ventaja de que dominaba toda la zona del Ebro y las comunicaciones con el Noroeste de España y con los Pirineos. 
Los astures, cántabros y vacceos insumisos, obligan a Roma a mantener una guerra de más ocho años. El sometimiento total de la península Ibérica se produce en el año 19 a.C. En este momento, a pesar de que Augusto afirma que toda la costa del océano obedece a los romanos, todavía en tiempos de Nerón hay algunos conatos de resistencia y se envían expediciones militares.

Por lo que se refiere a la Hispania Ulterior esta provincia presenta una manifiesta dualidad. Así, podía distinguirse nítidamente entre una zona meridional, escenario de una intensa colonización romana-itálica y una zona occidental con una menor concentración urbana y una todavía incipiente civilización. Por ello se considera conveniente desdoblarla en dos provincias independientes: la Bética, que toma su nombre del río Betis (actual Guadalquivir), que se restituye al régimen senatorial y la Lusitania que mantiene el régimen de provincia imperial. No se conoce con certeza la fecha de esta división provincial. En este sentido, a pesar de que Dión Casio, LIII 12.4 señala el propio año 27 a.C., los estudiosos, mayoritariamente, entienden que debe retrasarse esta fecha al año 13 a.C.

Queda así Hispania, a pesar de su configuración unitaria, ordenada en tres territorios provinciales. Esta triple división va a mantenerse, de forma estable con escasos cambios, a lo largo de casi dos siglos, hasta la definitiva reorganización de tiempos de Diocleciano. En el siglo III las provincias de Hispania constituyen la diocesis Hispaniarum encomendada a un vicarius del prefecto del pretorio y pasan a integrarse en la prefectura de la Galia. La antigua citerior se divide en tres: Tarraconensis, Carthaginiensis y Gallaecia; y la antigua ulterior continúa dividida en dos: Lusitania y Bética. Se añade a ellas una sexta provincia, la Mauritania Tingertina y posteriormente, en el 385 d.C. se configura la séptima, que será la Baleárica.

La inestable situación militar en el norte y este de la península provoca la construcción de numerosas calzadas en los primeros tiempos del Imperio debido a la presencia de importantes contingentes militares destacados y a la necesidad de su rápido desplazamiento. Incluso en época de Vespasiano todavía existen distintas guarniciones. Será en tiempos de Diocleciano cuando sólo se mantenga en Hispania la Legio VII Gemina, con asentamiento en la ciudad de León, a la cual da su nombre.

Por el contrario, el sur peninsular que conforma la Bética, fue muy pronto pacificado y se consolidó rápidamente un intenso proceso de romanización. En este sentido debe advertirse, que las tropas militares que se mantuvieron en la ciudad de Itálica no obedecen a necesidades bélicas frente a posibles sublevaciones contra la población autóctona, sino únicamente a medidas defensivas frente a eventuales ataques de los piratas del Rif que tenían sus asentamientos en las costas situadas frente a España. Como provincia senatorial, la Bética estaba gobernada por un procónsul elegido por un mandato de un año. Su cargo gozaba de gran prestigio en Roma, ya que se trataba de una provincia muy rica, con un elevado nivel cultural, con numerosas ciudades privilegiadas y con una abundante nobleza senatorial.

En palabras de Mommsen, si en algún lugar se había preparado especialmente la República romana para acometer con éxito la trascendental obra histórico-universal del Imperio, si en algún punto de la tierra conquistada Roma prepara la romanización del Occidente, es precisamente en España. 


\section{La ciudad, base de la administración de la península}

Sin perjuicio de defender la idea de que la Europa de las naciones es una derivación histórica de la organización provincial romana, entiendo que es preciso también reivindicar que la Europa de las ciudades es, asimismo, una indudable creación romana. A partir del concepto de civitas, consolidación y perfeccionamiento del concepto de polis griega, Roma se expande y se reproduce en los territorios que conquista, a través de la fundación o de la recreación de pequeñas unidades ciudadanas que se organizan desde el punto de vista político-administrativo a imagen y semejanza de la Urbs.

Sin perjuicio de que la organización provincial fue reglamentada con detalle desde la Metrópoli, puede afirmarse que la base fundamental de la administración imperial es fundamentalmente ciudadana. El concepto de civitas en Roma se encuentra integrado por dos dimensiones diferentes si bien complementarias: una urbana y otra sociopolítica. El Imperio Romano se expande y conforma fruto de la génesis, consolidación y crecimiento de un amplio elenco de ciudades de diversa condición estatutaria, que pueblan el mundo conocido y encarnan en cada territorio el progreso, la civilización y la cultura.

En pleno apogeo del Principado, paulatinamente, distintas ciudades preexistentes de la Bética asumieron la condición jurídica de municipios, desarrollados a partir de entidades preexistentes integradas, pacífica o forzosamente, en la comunidad política romana. Roma suplanta a través de su nuevo régimen ciudadano el orden existente en diferentes núcleos de población de origen púnico o griego.

Frente a los municipios, las colonias, como es bien sabido, fueron ciudades de nuevo cuño fundadas por Roma. En algunos casos, la población de las mismas procedía de proletarios de la Urbs que ven elevado su status social al convertirse en propietarios agrarios como consecuencia del reparto de tierra entre los mismos. En otros casos, las colonias de la Bética se conforman con veteranos legionarios tras su licenciamiento. En una y otra situación, serán auténticos catalizadores de una profunda y rápida romanización.

Analizando el origen y el proceso de romanización en la península, se observa que la primera en amoldarse a los usos y costumbres romanos fue la Bética. Su causa principal obedece no sólo al carácter abierto de sus habitantes y a su mayor grado de cultura -debido al trato asiduo con griegos y fenicios-, sino también, y muy principalmente, a que Roma favoreció las numerosas fundaciones de ciudades. Los avances más relevantes en materia de organización ciudadana se dan en dos etapas sucesivas: en primer lugar, la que comprende a la época de Julio César y Augusto; en segundo lugar, la que se corresponde con la etapa de la dinastía de los Flavios.

Por lo que hace a la primera etapa, a fines del siglo I a.C. son muchas las ciudades de la Bética que, aún sin poseer un estatuto jurídico romano, presentan ya un aspecto urbanístico y un ambiente social totalmente romanizado. Así César describe un foro y varios pórticos en Hispalis y refiere la existencia de una basílica al modo de las romanas en Corduba. Así en, 
His cognitis rebus, altera ex duabus legionibus, quae Vernacula appellabatur, ex castris Varronis, adstante et inspectante ipso, signa sustulit, seseque Hispalin recepit, atque in foro et porticibus sine maleficio consedit.

Caes. BC. 2.20 .4

...Ex contione se Cordubam recepit eoque ipso die tempore postmeridiano, cum in basilicam iret, quidam Minucius Silo cliens L. Racili libellum, quasi aliquid ab eo postularet...

Caes. Bell. Alex. 52

Una y otra ciudades tendrán su conventus civium romanorum antes incluso de ostentar el reconocimiento municipal romano.

Quod factum adeo eius conventus cives romanui comprobaverunt, ut domun ad se quisque hospitio cupidissime reciperet.

Caes. $B C 2.20 .5$

Ipse cum DC equibus magnis itineribus progreditur, edictumque praemittit, ad quam diem magistratus principisque omnium civitatum sibi esse praesto Cordubae vellet.Quo edicto tota provincia pervulgato, nulla fuit civitas, quin ad id tempus partem senatus Cordubam mitteret; nullusve civis romanus paulo notior, quin ad diem conveniret.

Caes. BC. 2.19. 2

Según Plinio, a fines del primer siglo del principado, en la Bética se contaban 175 ciudades. En tiempos de Augusto ya había crecido de forma importante el número de ciudades que alcanzaron el estatuto de municipio. Puede cifrarse en unos cincuenta los municipios de ciudadanos romanos y otros tantos los que habrían recibido el derecho latino. Sorprende que unos y otros no se hallen preferentemente en la costa, como solía suceder habitualmente en otros territorios. Por el contrario, en la Bética la fundación de ciudades se realiza preferentemente en el interior. La mayoría de los municipios béticos se conforman desde la existencia de antiguas poblaciones peregrinas, cuyos habitantes son honrados colectivamente con la ciudadanía o con la latinidad. Esta concesión y privilegio les obligaba a refundar su ciudad y a proveerla de las preceptivas instituciones político administrativas romanas.

A la cabeza de los municipios romanos de la Bética figuran Corduba (Córdoba) y Gades (Cádiz). Cicerón afirma que Balbo el joven se apropió del cargo de quattuorvir, lo que presupone que Gades era ya en ese tiempo municipio romano, siendo esta situación excepcional en la Hispania de su tiempo.

Balbus quaestor magna numerata pecunia, magno pondere auri, maiore argenti coacto de publicis exactionibus, ne stipendio quidem militibus reddito duxit se a Gadibus et triduum tempestate retentus ad Calpen Kal. Iuniis traiecit sese in regnum Bogudis plane bene peculiatus. His rumoribus utrum Gades referatur an Romam-ad singulos enim nuntios turpissime consilia mutat-, nondum scio. Sed praeter furta et rapinas et virgis caesos socios haec quoque fecit, ut ipse gloriari solet, eadem, quae 
C. Caesar: ludis, quos Gadibus fecit, Herennium Gallum histrionem summo ludorum die anulo aureo donatum in XIIII sessum deduxit-tot enim fecerat ordines equestris loci-quattuorviratum sibi prorogavit.

Cic., Ad fam. 10.32.3

Gades ocupó por mucho tiempo el lugar preeminente en la municipalidad bética, ya se considere el número de sus habitantes, ya su prosperidad y riqueza. Siendo el emporio económico más importante en su comercio con Italia. Ya en tiempo de Augusto contaba en su seno 500 caballeros romanos, un número mayor que el de cualquier otra ciudad del Imperio, a excepción de Padua y lógicamente de la propia Roma. Era además la capital del convento jurídico que llevaba su nombre. Merecen también especial mención entre los municipios de la Bética, Malaca y Salpensa. Junto a la progresiva concesión del estatuto municipal el rasgo más característico de la romanización del territorio peninsular hispano fue la fundación de diversas coloniae que se llevó a cabo sobre todo a partir del año 45 a.C. Suetonio afirma que se asentaron más de 80.000 ciudadanos romanos.

Octoginta autem civium milibus in transmarinas colonias distributis, ut exhaustae quoque urbis frequentia suppeteret, sanxit, ne quis civis maior annis viginti minorve quadraginta, qui sacramento non teneretur, plus triennio continuo Italia abesset, neu qui senatoris filius nisi contubernalis aut comes magistratus peregre proficisceretur; neve ii, qui pecuariam facerent, minus tertia parte puberum ingenuorum inter pastores haberent.

Sueton., Div. Iul. 42.1

En un principio existieron colonias de ciudadanos romanos, que eran las más importantes, y también colonias de derecho latino. La primera fundación colonial en la Bética fue Italica, que data del 206 a.C. fundada por Publio Cornelio Escipión con el fin de proporcionar tierras a sus veteranos. La establecida en Hispalis que en un primer momento fue partidaria de César y después de Pompeyo, fue tomada a viva fuerza y castigada por César con la confiscación de sus campos, los cuales distribuyó entre sus legionarios. Augusto concede el estatuto de colonia romana a Corduba (Córdoba) capital del convento jurídico y una de las ciudades más populosas e importantes de la Bética. Otras colonias romanas representativas en la Bética son: Urso (Osuna), Ucubi (Espejo) y Hasta (Mesa de Asta).

En su estadio inicial, el estatuto de colonia en la Bética surge como un castigo de César frente a diversas poblaciones que en las guerras civiles habían apoyado las tropas de Pompeyo, el triunviro derrotado. Resulta paradójico, desde el conocimiento de este origen, que en tiempos más evolucionados este estatuto fuera codiciado ya que a él aspiraron muchas ciudades ya constituidas y reguladas jurídicamente. En este sentido se puede hablar de colonias titulares, que se hacen frecuentes en época de Trajano y Adriano, en las que el reconocimiento del pleno derecho colonial se otorga a una previa población que ya era municipio romano o latino. Un ejemplo elocuente de esta categoría de colonias en la Bética lo representa Itálica a quien Adriano le concede el derecho colonial. Dión Casio refiere que Itálica debió tal privilegio por haber 
nacido en su suelo los emperadores Trajano y Adriano. Con carácter general puede afirmarse que son los emperadores Flavios quienes inician una preocupación política por los territorios provinciales que supere el mero interés coyuntural consistente en el objetivo de conseguir ciertos recursos materiales o determinadas rentas tributarias.

Esta nueva orientación flavia tiende a un proceso de equiparación con Italia. En este marco general las provincias de Hispania reciben un decidido reconocimiento. La ruptura con el monopolio de los privilegios ciudadanos a favor de Italia se manifiesta de forma notoria con la concesión del ius Latii a Hispania. Esta medida adoptada por Vespasiano, en el año 72 d.C., con ocasión de un censo ordenado para todo el Imperio, estaba sin duda plenamente justificada, como afirma Estrabón, por los grandes niveles de romanización existente. El significado de esta concesión ha sido $-\mathrm{y}$ sigue siendo-muy discutido. Para algunos autores, solamente determinadas ciudades peregrinas, sobre todo de la Bética, se configuraron como municipios flavios. En todo caso, sin entrar en esta ardua cuestión, la concesión del estatuto de municipio latino convertía en latinos a una gran parte de la población libre de las ciudades y además producía la posibilidad de la concesión de la ciudadanía romana per honorem que consistía, como es conocido, en que los miembros de las oligarquías locales que accedían al desempeño de las distintas magistraturas en un municipio latino, se convertían en ciudadanos romanos junto con todos los que estuvieran bajo su patria potestad.

El ius Latii de Vespasiano estableció, pues, las bases estatutarias para la integración en la ciudadanía romana de grandes masas de la población hispana y posibilitó que muchas ciudades abandonaran el uso del derecho local tradicional para reglamentar su vida conforme al orden jurídico romano. Dado el carácter anual en el desempeño de las magistraturas y la necesaria ocupación de las mismas por personas distintas, en unos pocos años, la práctica totalidad de las oligarquías locales gozaron de la ciudadanía romana. Cada nuevo municipio se organizaba a semejanza de los municipios de Italia. Todos contaban con una ley que reglamentaba su funcionamiento. Hoy es casi pacífico en la doctrina la admisión de una Ley Flavia Municipal, que sería marco general en la que se inspirarían las concretas leyes municipales de la Bética que conocemos fragmentariamente, a través de las distintas planchas de bronce que de ellas se han encontrado. Los especialistas en epigrafía datan la factura de dichas planchas en tiempos de Domiciano, lo que probaría la continuidad política respecto de la medida adoptada por su padre.

Bajo los Flavios se configura una precisa organización del culto imperial, así puede constatarse un floreciente culto en Corduba que provoca, asimismo, una rica vida asociativa religiosa en la que se integran las oligarquías locales. Las ciudades a pesar de ser diseñadas según patrones político-administrativos establecidos por el gobierno central gozaron de un apreciable nivel de autonomía. La política municipal era la que más directamente percibían sus habitantes.

Un buen ciudadano de Roma se sentía orgulloso de su pertenencia a la colonia o municipio en que había nacido y residía. Las ciudades romanas en la Hispania romana compitieron en ofrecer la mejor apariencia, ornamentando sus espacios públicos con arcos, exedras, estatuas, etc. Parte de esa monumentalización fue financiada con 
caudales municipales y con el patrimonio de las oligarquías locales, solo excepcionalmente se costearon con fondos imperiales.

\section{Algunos datos económicos de la Hispania romana}

En el análisis de la economía se hace preciso diferenciar la época republicana de la época imperial. En la primera etapa fue considerada un simple territorio de explotación. En la segunda se constituye como un centro de inversión de capitales tanto para el mejor aprovechamiento de explotaciones agrarias como para su aplicación a diversas actividades mercantiles e industriales. Hispania figura entre las provincias más ricas desde el punto de vista agrícola. Entre los productos de su natural fecundidad, sobresalían los cereales. Hispania es una península frumentaria. También es importante el vino y el aceite, de los cuales había un comercio activo y sostenido con Italia. Un funcionario imperial, con residencia fija y permanente en Hispalis, cuidaba de hacer el acopio de estos productos para atender a las necesidades de la capital del mundo. Además exportaba a Roma miel y cera.

La civilización romana provoca en la agricultura un cambio sustancial de su régimen jurídico ya que pasó a basarse en los principios romanos de propiedad privada, municipal y estatal. La fundación de nuevas colonias conllevó la potenciación de la propiedad privada, lo que implicó un cambio radical, pues, en la península se mantenía un sistema de propiedad colectiva. Se aprecia también la creación de grandes latifundios en los que se inicia la utilización de la mano de obra esclava.

En siglo I d.C. se introducen avances importantes tales como los regadíos, el barbecho o el arado romano. En los censos llevados a cabo en tiempos de Augusto, ningún municipio romano registró tal cantidad de gentes ricas como Gades. Con sus típicos comerciantes al por mayor, fue la primera ciudad fuera de Italia que adoptó el derecho romano y la lengua de Roma. Las ciudades de la península fueron auténticos emporios económicos de todo el territorio que de ellas dependía administrativamente, tanto las aldeas (vici) como las explotaciones agrícolas (villae).

En la ciudad radicaban las principales actividades artesanales y colegios profesionales, al tiempo que se configuraron como centros de manifestaciones culturales y artísticas. Este nivel de riqueza material se correspondía con una refinada opulencia de las costumbres. La proximidad de Italia y las cómodas y baratas comunicaciones por mar abrían una espléndida ruta para colocar sus productos en el primer mercado del mundo. Es probable que Roma no llegase a mantener con ningún otro territorio un comercio al por mayor tan importante y tan asiduo como con Hispania. El comercio de Roma con Hispania logró lo que la conquista militar había cimentado. Las monedas romanas de plata circularon en la península con anterioridad a su utilización en otras provincias fuera de Italia.

Otro de los recursos naturales en el que Roma demostró un gran interés fue la explotación de sus yacimientos. Debido a distintas medidas eficaces de gestión se produce un incremento notable de la producción. Roma en Hispania modifica el régimen jurídico minero. Fue frecuente su cesión en arrendamiento a particulares. A fines 
del siglo I d.C. comienza la explotación por compañías dirigidas por funcionarios del estado. Los principales yacimientos en la Bética se situaron en las estribaciones de Sierra Morena.

La actividad industrial constituyó fundamentalmente un complemento de la actividad agraria y se desarrolló desde muy temprano, así las industrias de salazones, vino, aceite. También existió una industria próspera en el sector del hierro y de los tejidos de lana y lino, que fue muy apreciada en la Ubrs debido a su magnífico acabado y carácter artesanal. Con el tiempo la industria bética experimentará un gran desarrollo derivado fundamentalmente de la transformación manufacturada de productos agropecuarios y orientada preferentemente a mercados extrapeninsulares.

La viticultura, la oleicultura y las relaciones comerciales llevaron a nuestro litoral a una afluencia regular de comunicación con los habitantes de la península itálica. El desarrollo del comercio estuvo favorecido por la consolidación política de Roma en todo el Mediterráneo y se vio facilitado por la creación de un importante sistema de comunicaciones representado por las calzadas que se construyeron en Hispania. Esta red llegaba desde Roma y a través de más de 34 itinerarios peninsulares llegó a conectar todas las principales ciudades.

Es elocuente el cuidado con que Roma atendió a la red de calzadas en Hispania. Entre los Pirineos y Tarragona se han descubierto piedras miliares romanas procedentes de los últimos tiempos de la República de mayor antigüedad que cualquier otra provincia del Occidente. Si bien es cierto que Augusto y Tiberio fomentaron la construcción de caminos por razones militares, también lo es que muchas de las calzadas béticas sólo pueden obedecer a fines comerciales. A razones económicas se debe la gran calzada del Imperio que llevaba el nombre de Augusto que después de atravesar los Pirineos por el Puigcerdá bordea el mar hasta Tarraco y de allí a través de Valentia llega a la desembocadura del Júcar para internarse, tierra adentro, hasta alcanzar el valle del Betis y continuar atravesando toda la Bética hasta la desembocadura del Guadalquivir a fin de comunicar Roma con el océano. Asimismo, se potenció un mejor aprovechamiento de las vías fluviales para el transporte sobre todo de mercancías. En suma, puede concluirse diciendo que Hispania participó especialmente de la libertad de comercio establecido por Roma en todo el Mediterráneo lo que supuso para esta provincia un importante estímulo para su actividad mercantil.

\section{Postfatio}

Termino con dos citas elocuentes. En primer lugar, con el célebre brindis de Marcelino Menéndez Pelayo que realiza a los postres de una cena ante colegas de todas las naciones europeas, que se reunían en un congreso para conmemorar el centenario de Calderón de la Barca:

Brindo por lo que nadie ha brindado hasta ahora: por las grandes ideas, convicciones y creencias que fueron alma, esencia e inspiración de España... Brindo también por el municipio español, hijo glorioso del municipio romano y expresión éste de la verdadera libertad española...Brindo, en suma, por todos los habitantes de las diver- 
sas naciones latinas, que, como arroyos, han venido a mezclarse en el grande océano de nuestro común origen de la gente romana. ${ }^{1}$

En segundo lugar, con una luminosa reflexión de Rodríguez Adrados:

Y cuando se da un golpe de azada o de tractor, salen a la luz los más ilustres bronces romanos con leyes y edictos o con las más bellas esculturas o mosaicos. Queda Córdoba y Sevilla y Cádiz y Osuna y también por qué no Granada. Granada era una Florentia Illiberritana...Y en su museo, como en los de... tantas otras ciudades andaluzas, quedan abundantes testimonios de la herencia romana. Cierto que para los más Granada es la Alhambra y que la Alhambra es, qué duda cabe, el más espléndido de los palacios árabes. Pero ¿qué es la Alhambra sino una mansión romana, con su peristilo que es el patio de los leones...No se trata de desdeñar a nadie, cada cual ha jugado su papel en la historia. Pero hay que hacer hablar a los hechos y olvidar los tópicos manidos. Griega y romana y cristiana es la base y la espina vertebral de nuestra Andalucía. ${ }^{2}$

Federico García Lorca, con el que he iniciado mi reflexión, lo adivinaba ya pues su sentido de la vida y de la tragedia tenía mucho de hispano y de romano, en suma, todo en uno.

1 Vid. Menéndez Pelayo, M., Brindis del Retiro. Discurso pronunciado el 30 de mayo de 1881, analizado y reproducido en numerosas publicaciones.

2 Vid. Rodríguez Adrados, F., Roma Andaluza, en Tercera de ABC, 16 junio 1998. 